\title{
Taxonomic and faunistic study of Aulacidae (Hymenoptera, Evanioidea) from Iran, with illustrated key to species
}

\author{
Mostafa Ghafouri Moghaddam ${ }^{1}$, Giuseppe Fabrizio Turrisi ${ }^{2}$ \\ 1 Department of Plant Protection, College of Agriculture, University of Zabol, Zabol, P.O. Box: 98615-538, I. R. IRAN \\ 2 Via Cristoforo Colombo 8, 95030, Pedara, Catania, Italy \\ http://zoobank.org/583BCCD1-F6E1-492A-A0CE-5E1DB5114477 \\ Corresponding author: Mostafa Ghafouri Moghaddam (ghafourim@uoz.ac.ir)
}

\begin{abstract}
Received 24 November 2017

Accepted 24 January 2018

Published 2 February 2018

Aulacidae are parasitoids of wood-boring larvae of Hymenoptera and Coleoptera, known in all zoogeographic regions of the World, except Antarctic. Two aulacids, Pristaulacus compressus (Spinola, 1808) and the rare Pristaulacus mourguesi Maneval, 1935, have been recently collected from Iran, the latter being a new record. Based on available data,

Academic editor: the Iranian aulacid fauna includes five species within a single genus, Pristaulacus Kieffer

Michael Ohl 1900. A brief taxonomic treatment, as well as morphometric data and an illustrated key to species, are provided.
\end{abstract}

\section{Key Words}

\section{Pristaulacus}

Western Iran

wood-boring

parasitoid

illustrated key

\section{Introduction}

The aulacid wasps, Aulacidae Shuckard, 1842 are endoparasitoids of wood-boring larvae Coleoptera (Cerambycidae and Buprestidae) and Hymenoptera (Xiphydriidae). The family Aulacidae is small distinct family in the superfamily Evanioidea. This family includes 262 extant species grouped within only two genera, Aulacus Jurine, 1807 with 83 species and Pristaulacus Kieffer, 1900 (including the former Panaulix Benoit, 1984), with 177 species (Jennings and Austin 2004, Turrisi et al. 2009, Chen et al. 2016, Turrisi and Nobile 2016; Turrisi 2017). According to the online Taxapad (Yu et al. 2012) this family contains four subfamilies and 11 genera, including fossils. Some identified fossils are not completely known and their inclusion within Aulacidae still remains somewhat questionable (Zhang and Rasnitsyn 2004).
Some evidence support strongly a close relationship between Aulacidae and Gasteruptiidae and each group are currently considered as distinct families (Jennings and Austin 2000, Turrisi et al. 2009). However, the current generic classification of the Aulacidae is not sufficiently robust and needs further study. There is strong support for the monophyly of Pristaulacus but not for Aulacus, which is largely paraphyletic in the cladistics analyses of Turrisi et al. (2009). The faunistic knowledge of Aulacidae is generally unsatisfactory due to their general rarity and difficulty in collecting by conventional methods, e.g., by net; there is a general paucity of available material, even in the large museums (Turrisi 2007).

The Iranian Aulacidae has been recently treated by Ghahari (2012), Lotfalizadeh et al. (2017) and Ghahari and Madl (2017). Nonetheless, continuous sampling in different ecosystems, particularly with Malaise traps, has resulted in new records which we present in this paper, along with an illustrated key to species. 


\section{Material and methods}

The specimens examined in the present paper have been recently collected using a modified Malaise-trap (Funnel-Townes Style, B. Motamedinia, unpublished: BMMTF-TS) placed in various localities of Kermanshah province (Western part of Iran), as well as in Eastern provinces (Fig. 1A-B). The traps were a basic Malaise trap supplemented with an additional internal collecting bottle. The insects bump into the black mesh panel and move towards the lighter mesh to escape due to their positive phototropism (van Achterberg 2009); at this point, they encounter the collection bottle and become permanently trapped. However, a considerable number of in-
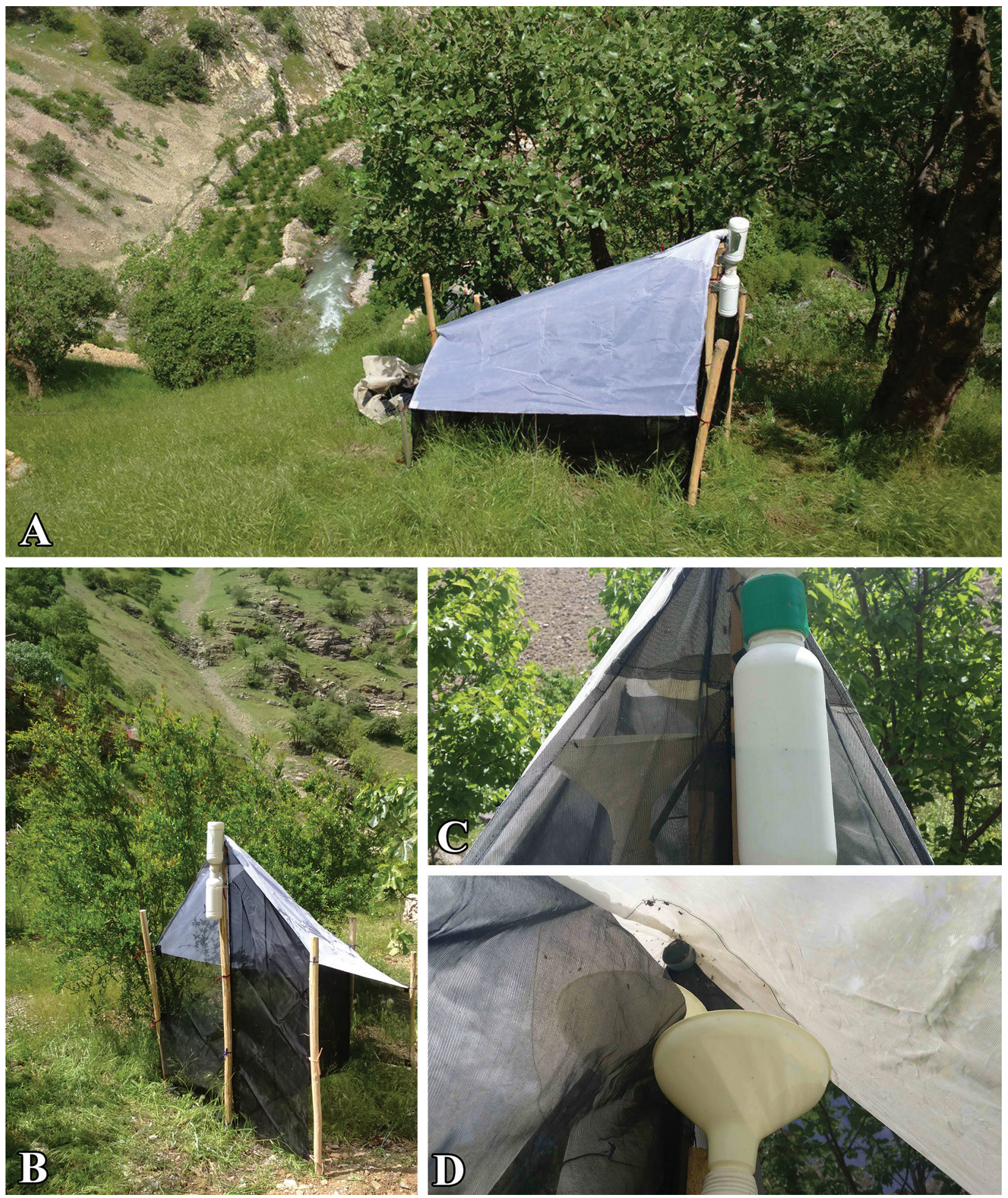

Figure 1. Malaise traps; locations. A Kermanshah province, Dudan, adjacent to the river and valley; B Kermanshah province, Harsin, near the foothills; $\mathbf{C}$ and $\mathbf{D}$ Additional collecting bottle inside the trap. 
sects fail to enter the collecting bottle for various reasons e.g., inappropriate installation of trap or collecting bottle, displacement of the trap by wind, or the particular behavior of the insects (Fig. 1C-D). The collected specimens were killed in $75 \%$ ethanol and then glued on triangular cards, according to AXA protocol (van Achterberg 2009). Finally, all of the specimens labeled using new pinning block (Ghafouri Moghaddam et al. 2017).

Specimens were examined under a Nikon ${ }^{\circledR}$ SMZ645 stereomicroscope (Nikon ${ }^{\circledR}$ Inc., Japan). Illustrations of taxonomically important body parts were taken using a Canon $^{\circledR}$ EOS 700D (Canon ${ }^{\circledR}$ Inc., Japan), a simple light source with halogen lamp (manual) and $2 \times$ lenses mounted on Hund ${ }^{\circledR}$ Stereomicroscope (Wetzlar Inc., Germany). Multiple images were subsequently processed in Zerene Stacker ${ }^{\mathrm{TM}}$ version 1.04 software and post processed in Adobe Photoshop ${ }^{\circledR}$ CS6. The images in the illustrated key were prepared by the second author using voucher specimens already deposited in his private collection. Morphological terminology follows Crosskey (1951), Huber and Sharkey (1993) and Turrisi (2007). Terminology for surface sculpturing follows Harris (1979). A distributional map was generated using SimpleMappr (Shorthouse 2010) and collecting localities are given in Fig. 8. The following abbreviations are used for depositories: CPTO: Guido Pagliano collection, Torino, Italy; DPPZ: Collection of Department of Plant Protection, University of Zabol, Iran; DU: Depository Unknown; MCSN: Museo Civico di Storia Naturale "G. Doria”, Genova, Italy; MNHN: Muséum National d'Histoire Naturelle, Laboratoire d'Entomologie, Paris, France; NHMW: Naturhistorisches Museum, Wien, Austria; ZIN: Zoological Institute of the Russian Academy of Sciences, St. Petersburg, Russia; ZMUC: Zoological Museum, Copenhagen University, Denmark.

Measurements were done with a micro-ruler. Morphometric ratios were measured in tpsDig ver. 2.05 (Rohlf 2006), using digitized coordinates of landmarks and capture outlines. It should be noted that we documented measurements to the nearest $0.001 \mathrm{~mm}$ with tpsDig, but we conservatively report them to an accuracy of two decimal places. Definitions and abbreviations for the measured characters are shown in Table 1 (see also Figs 2, 3, 5).

Table 1. Abbreviation for morphometric data, measured in the examined material.

\begin{tabular}{|c|c|c|}
\hline Abbreviation & Definition & Explanation \\
\hline CIL & Clypeal maximum length & Full-face view, as in Fig $5 \mathrm{~A}$ \\
\hline $\mathrm{CIOL}$ & Clypeus-ocellar line & Distance between base of clypeus and median ocellus, full-face view (Fig 5A). \\
\hline CIW & Clypeal maximum width & Full-face view, as in Fig $5 \mathrm{~A}$ \\
\hline CoL & Hind coxa maximum length & In lateral view, as in Fig 3C \\
\hline CoW & Hind coxa maximum width & In lateral view, as in Fig 3C \\
\hline EL & Eye maximum length & Vertical line length of compound eye, full-face view (Fig 2A) \\
\hline EW & Eye maximum width & Horizontal line, width of the compound eye, full-face view (Fig 2A) \\
\hline FWL & Fore wing maximum length & From median margin of first axillary sclerite to distal point of wing blade, as in Fig $3 \mathrm{~A}$ \\
\hline FWW & Fore wing maximum width & Longest line drawn perpendicular to the length axis, as in Fig $3 \mathrm{~A}$ \\
\hline HL & Head maximum length & From anterior prominence of head to base of occipital carina, dorsal view (Fig 2B) \\
\hline HW & Head maximum width & Maximum distance between lateral margins of compound eyes dorsal view (Fig 2B) \\
\hline IOL & Inter-ocular line & Shortest distance between inner margin of compound eyes, full-face view (Fig 2A) \\
\hline MsL & Mesosoma maximum length & $\begin{array}{l}\text { longest anatomical line that connects the posterior-most point of the propodeal lobe } \\
\text { with the anterior-most point of the pronotum, but if one of the reference points is not } \\
\text { visible, dorsal view may help, preferentially in lateral view (Fig 2D) }\end{array}$ \\
\hline MsW & Mesosoma maximum width & In dorsal view, as in Fig $2 \mathrm{E}$ \\
\hline MtL & Metasoma maximum length & From base of petiole to base of pygidium, lateral view (Fig. 3B) \\
\hline OD & Ocellar diameter & In dorsal view, as in Fig 2B \\
\hline OML & Ocular-mandibular line & $\begin{array}{l}\text { Minimum distance between anterior margin of compound eye and mandibular } \\
\text { insertion to head, full-face view (Fig } 5 \mathrm{~A} \text { ) }\end{array}$ \\
\hline OOCL & Ocular-occipital carina line & $\begin{array}{l}\text { Minimum distance between lateral margin of compound eye and base of occipital } \\
\text { carina lateral view (Fig } 2 \text { C) }\end{array}$ \\
\hline OOL & Oculo-ocellar line & Shortest distance between margins of compound eye and ocellus, dorsal view (Fig 2B) \\
\hline OTL & Oculo-tentorial line & $\begin{array}{l}\text { Minimum distance between anterolateral margin of compound eye and tentorial pit, } \\
\text { full-face view (Fig } 5 \mathrm{~A} \text { ) }\end{array}$ \\
\hline PEL & Petiole maximum length & From anterior-most margin to posterior margin of petiole, dorsal view (Fig 2F) \\
\hline PEW & Petiole maximum width & Dorsal view, as in Fig $2 \mathrm{~F}$ \\
\hline PL & $\begin{array}{l}\text { Propodeum maximum } \\
\text { length }\end{array}$ & From apex of scutellum to base of petiole, dorsal view (Fig 2E) \\
\hline POL & Posterior-ocellar line & Shortest distance between margin of lateral ocelli, dorsal view (Fig 2B) \\
\hline PSL & $\begin{array}{l}\text { Pterostigma maximum } \\
\text { length }\end{array}$ & 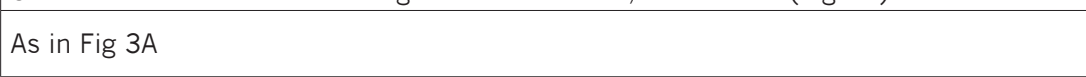 \\
\hline PSW & Pterostigma maximum width & As in Fig $3 \mathrm{~A}$ \\
\hline PW & Propodeum maximum width & In dorsal view, as in Fig 2E \\
\hline TL & Temple maximum length & $\begin{array}{l}\text { Minimum distance between anterior margin of compound eye and base of occipital } \\
\text { carina, dorsal view (Fig 2B) }\end{array}$ \\
\hline
\end{tabular}




\section{Results}

Five species belonging to the genus Pristaulacus are recorded from five provinces of Iran (East-Azarbaijan, Guilan, Kermanshah, Shiraz and West Azarbaijan) (Fig. 8). The species recorded for the first time from Iran and from individual provinces are marked with a single $(*)$ or double $(* *)$ asterisks, respectively. It should be noted that no depository was mentioned for specimens of both $P$. barbeyi and $P$. galitae from Iran (Ghahari 2012), thus, it has not been possible to examine this material for confirmation. These taxa are marked below with an \#.

\section{Illustrated key to Iranian Pristaulacus Kieffer}

1 Lateroventral margin of pronotum without tooth-like process (a)

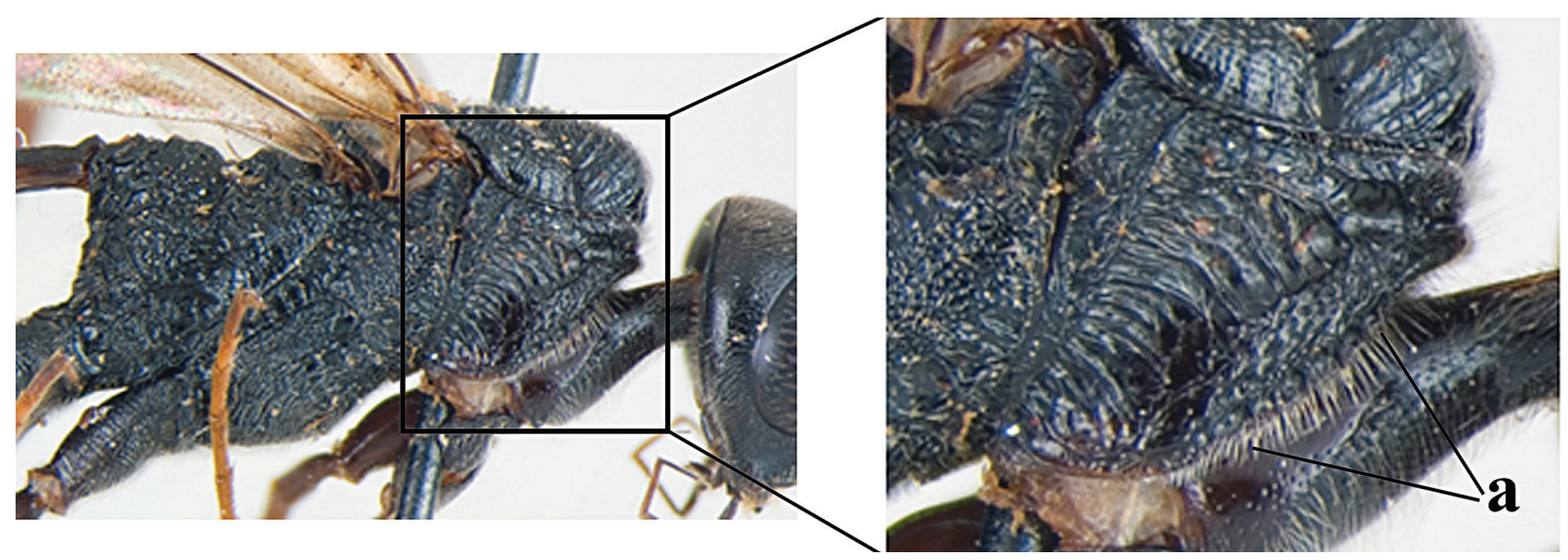

- Lateroventral margin of pronotum with at least one tooth-like process (aa)

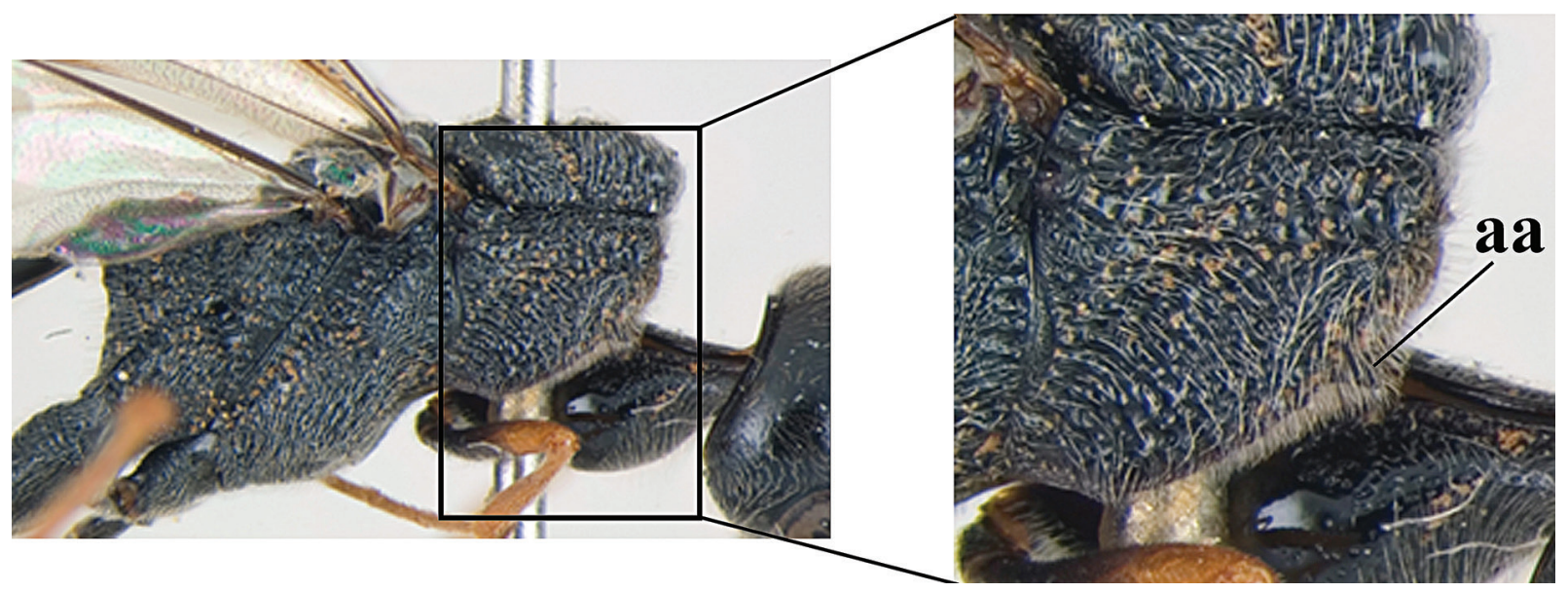

2 Head dull to weakly shiny, extensively transverse striolate (a); hind tarsus dark brown; tarsal claw with two tooth-like processes (b); petiole stocky and short (c)...... P. barbeyi (Ferrière, 1933)
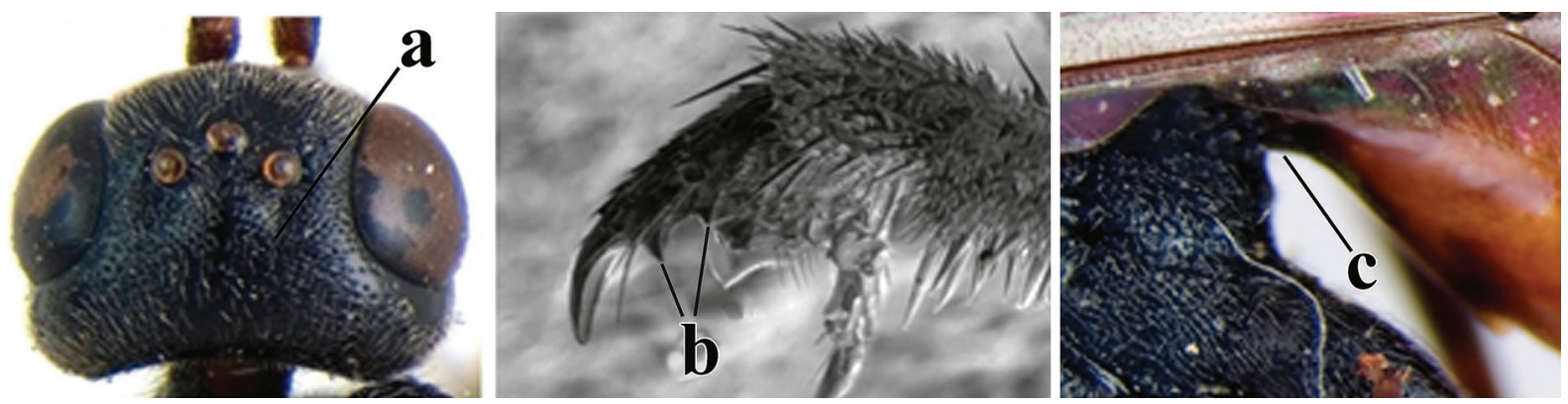
- Head shiny, mostly polished, except frons weakly striolate punctate (aa); hind tarsus yellow; tarsal claw with four tooth like processes (bb); petiole slender and elongate $(\mathbf{c c})$.....

P. gloriator (Fabricius, 1804)
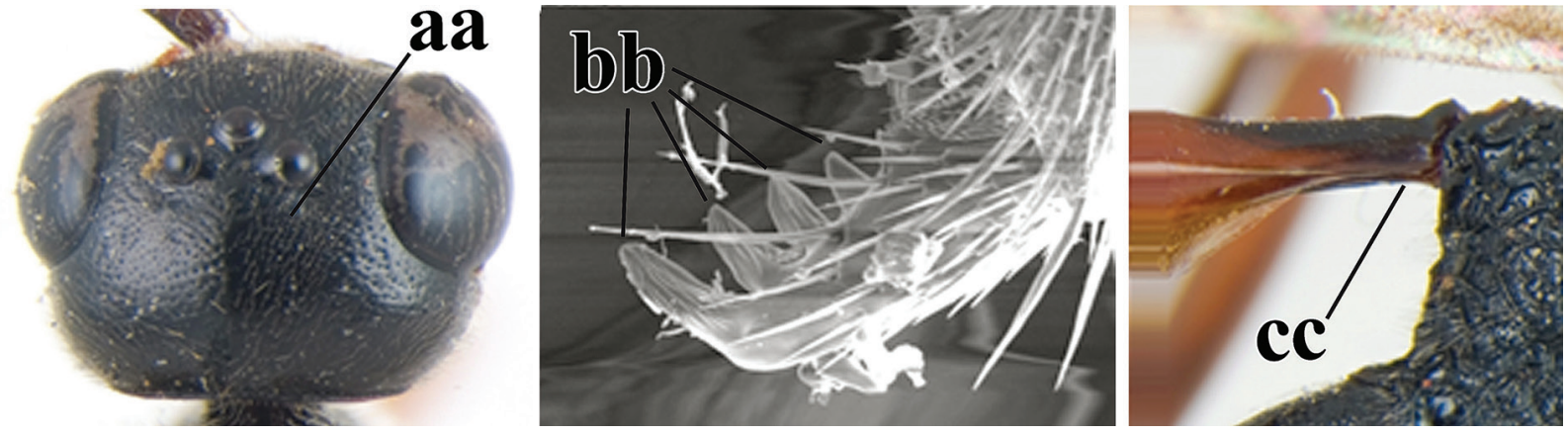

3 Lateroventral margin of pronotum with one tooth-like process (see first couplet).....

- Lateroventral margin of pronotum with two tooth-like processes (aa) P. compressus (Spinola, 1808)

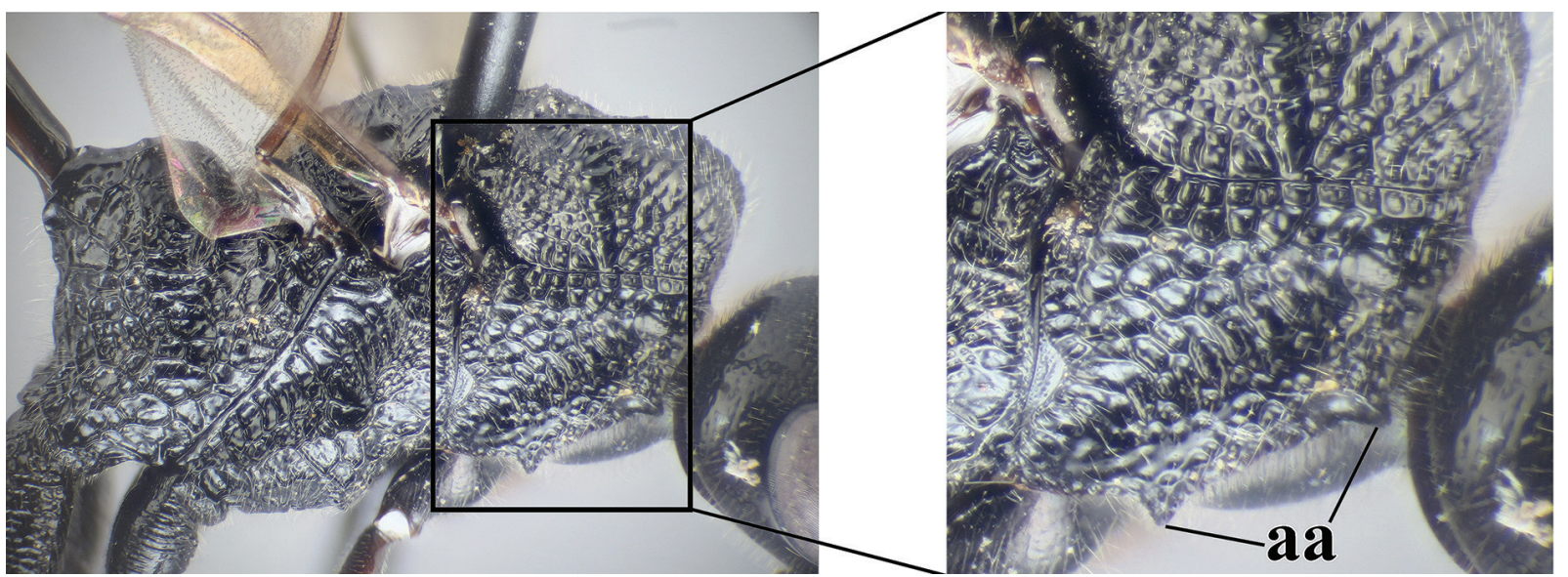

4 Large sized species (body length, excluding ovipositor, 16.5-18.5 mm); occipital carina rim-like, blackish, 0.2× diameter of an ocellus (a); hind basitarsus weakly but distinctly curved, 1.5x longer than tarsomeres 2-5 (b); ovipositor 1.4x fore wing length P. mourguesi Maneval, 1935

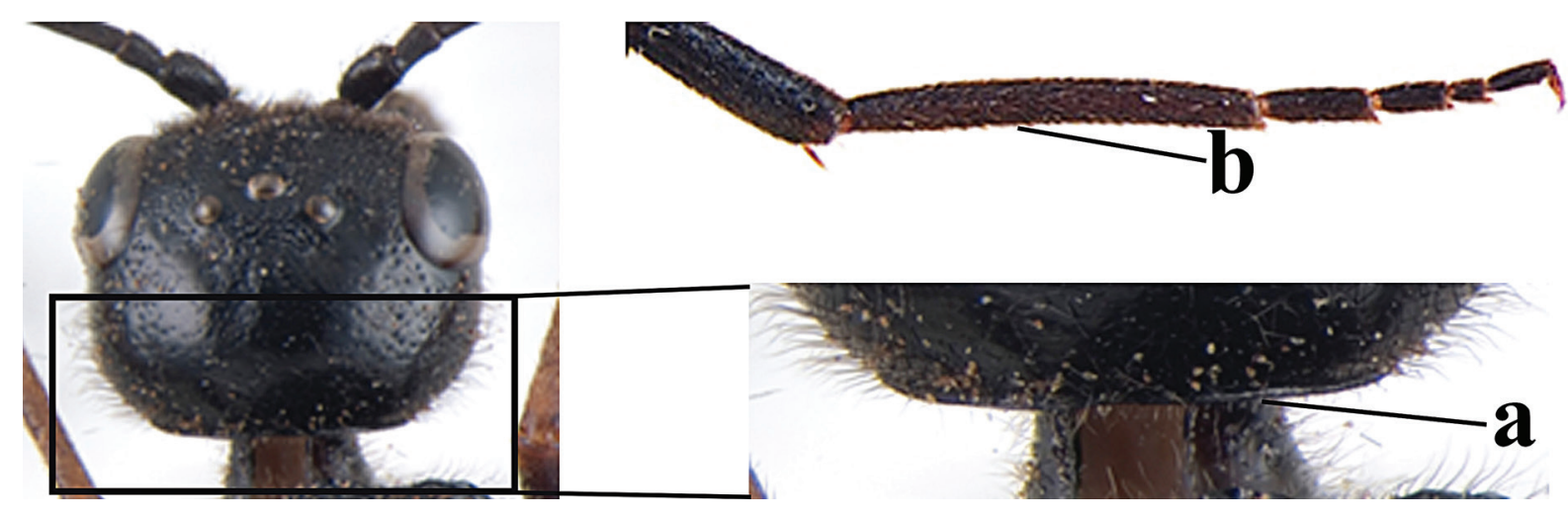


- Medium sized species (body length, excluding ovipositor, 8.0-11.5 mm); occipital carina cerciniform, brownish, 0.5x diameter of an ocellus (aa); hind basitarsus straight, 1.1× longer than tarsomeres 2-5 (bb); ovipositor 1.2× fore wing length . P. galitae (Gribodo, 1879)
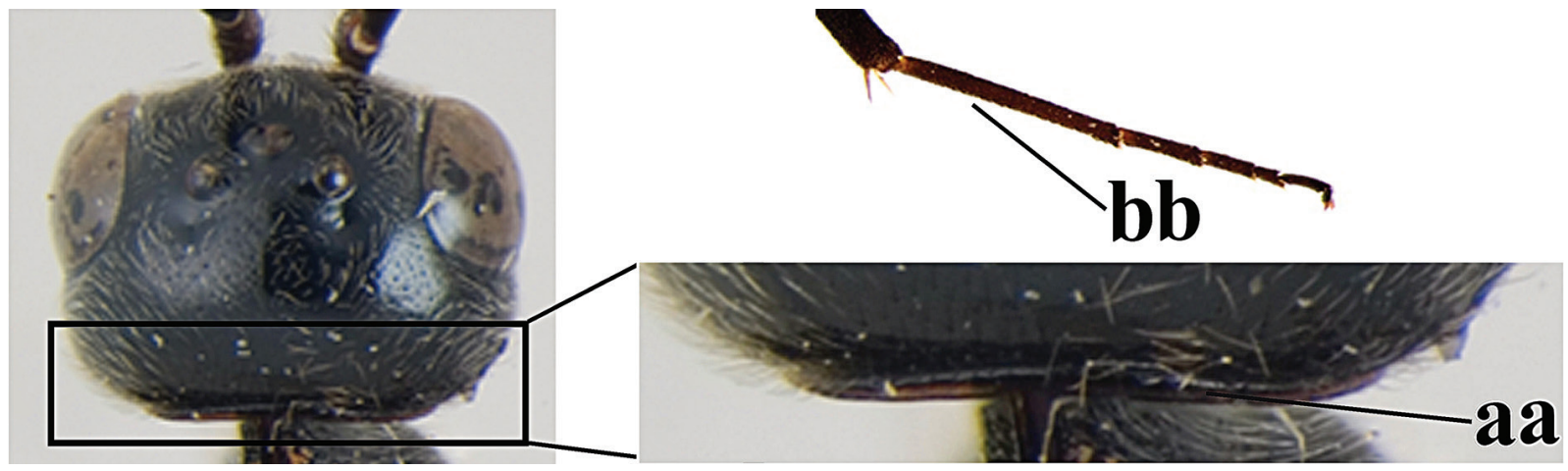

Family Aulacidae Shuckard, 1842

Pristaulacus Kieffer, 1900

\section{Pristaulacus barbeyi (Ferrière, 1933) \#}

Odontaulacus barbeyi Ferrière, 1933: 141, Holotype $q$ and paratype ふ..- Algeria, Babor (MNHN).

Distribution. Algeria, Greece, Morocco, Spain, Turkey (Turrisi 2007) and Iran (Ghahari 2012; Turrisi 2013a, b, c).

Distribution in Iran. West Azarbaijan province (Ghahari 2012: DU).

Diagnosis. $P$. barbeyi is a small to medium-sized species, with body length (excluding ovipositor) of 6.7$11.8 \mathrm{~mm}$, fore wing length $5.1-8.1 \mathrm{~mm}$; ovipositor length $1.3 \times$ fore wing length (holotype), but variable length among specimens from Turkey. It is readily distinguished by the shape of the head with a very narrow cerciniform occipital carina (width less than $0.2 \times$ ocellus diameter), rounded latero-ventral margin of pronotum without tooth-like processes, tarsal claw bearing two tooth-like processes along the inner margin, and a short and stocky petiole.

Hosts. Ghahari (2012) mentioned an unknown Buprestidae as host of this species in Iran, living on Abies.

\section{Pristaulacus compressus (Spinola, 1808) **}

Figs 2, 3, 4

Aulacus compressus Spinola, 1808: 48, Holotype ㄱ. - Italy, Liguria, Habitat in montibus Orerii (MCSN).

Specimens examined. 29 , DPPZ. Iran, Kermanshah province, Dudan, $35^{\circ} 01^{\prime} 00^{\prime \prime} \mathrm{N}, 46^{\circ} 11^{\prime} 32^{\prime \prime} \mathrm{E}, 1155 \mathrm{~m}$, 20.VI.2016, Malaise trap no. 2 mounted in orchard, leg.: M. Zardouei Heidari; 1 , , DPPZ. Iran, Kermanshah province, Harsin, $34^{\circ} 16^{\prime} 18.89$ 'N, 47³6'16.63”E, 1568 $\mathrm{m}, 05$. VII.2016, Malaise trap no. 1 mounted in orchard, leg.: M. Zardouei Heidari.

Distribution. Austria, Bulgaria, Czech Republic, France, Germany, Greece, Hungary, Iran, Iraq, Italy, Lebanon, Morocco, Poland, Romania, Russia (western territories), Slovakia, Spain, Switzerland, Turkey, Ukraine and former Yugoslavia (Madl 1990, Turrisi 2007, 2011, 2013a).

Distribution in Iran. Shiraz (Madl 1990: 114, NHMW), East-Azarbaijan (Lotfalizadeh et al. 2017: DU), and Kermanshah province (new record).

Diagnosis. It is a medium sized species with a body length of 8.8-14.2 mm (excluding ovipositor), fore wing length $6.6-9.5 \mathrm{~mm}$. It is readily distinguished by having a wide occipital carina (width equal to ocellus diameter), a pair of tooth-like processes on each latero-ventral margin of pronotum, reddish-orange hind tarsus, and ovipositor length $1.1-1.3 \times$ fore wing length.

Morphometric ratios. CIOL/ClL: 1.10; ClL/ClW: 3.33; ClW/OML: 0.69; CoL/CoW: 2.61; EL/EW: 2.42; EL/ OML: 2.90 ; EW/OOCL: 0.40; EW/OTL: 1.21; FWL/ FWW: 3.10; HL/ClL: 4.04; HL/TL: 2.07; HW/EW: 9.48; HW/HL: 1.21 ; IOL/CIOL: 1.36; IOL/EW: 2.91; IOL/ HW: 0.30; IOL/OML: 3.48; MsL/MsW: 2.18; MtL/MtW: 2.57; PEL/PEW: 1.90; PL/PW: 0.67; POL/OD: 1.46; POL/OOL: 1.00; SL/SW: 2.89; TL/EL: 1.55.

Hosts. This species was reared from Chlorophorus adelii Holzschuh, 1974 (Coleoptera, Cerambycidae) in tree oak, Quercus sp. (Madl 1990, Wall 1994). The reared beetle is polyphagous on deciduous trees and is endemic to Iran (Holzschuh 1974).

Remarks. The distribution of this species covers mainly the European area (see Turrisi 2011). It shows some 

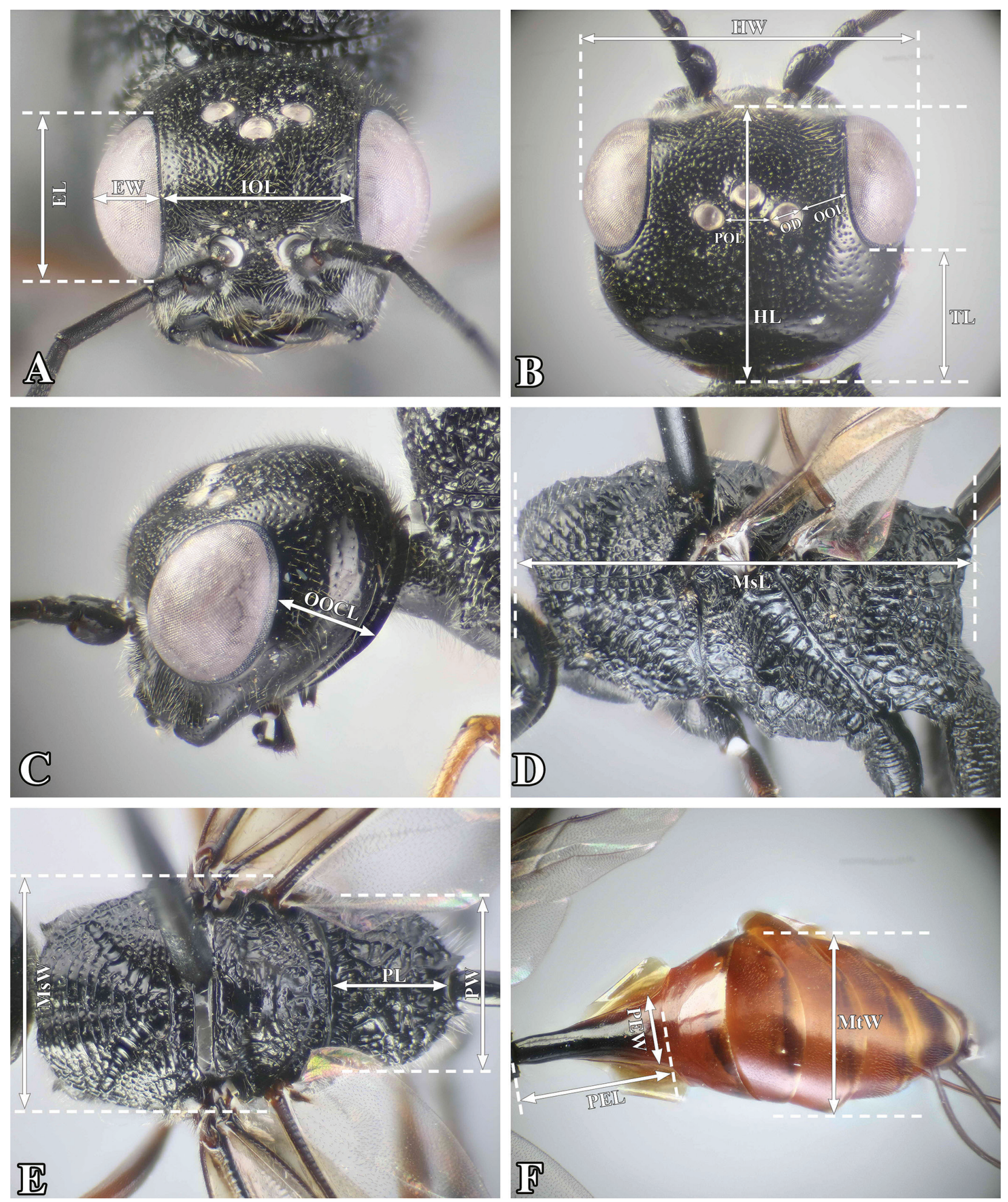

Figure 2. Pristaulacus compressus Spinola 1808. female (Iran): A face, frontal view; B head, dorsal view; C head, lateral view; D mesosoma, lateral view; E mesosoma, dorsal view; F petiole and metasoma, dorsal view.

intraspecific variation in colour and sculpture of some parts of the body (Turrisi 2007). The most similar species is P. lindae Turrisi, 2000, having hind tarsi blackish brown, metasoma more extensively red orange, different shape of mesosoma, sculpture of prescutum carinulate rugulose, a longer petiole and ovipositor (see Turrisi (2007, 2011 for more details). The head bears a coarser punctuation than European specimens of $P$. compressus and $P$. lindae, but less so than the other two similar species P. samai Turrisi, 2011 and P. rapuzzii Turrisi, 2011. 

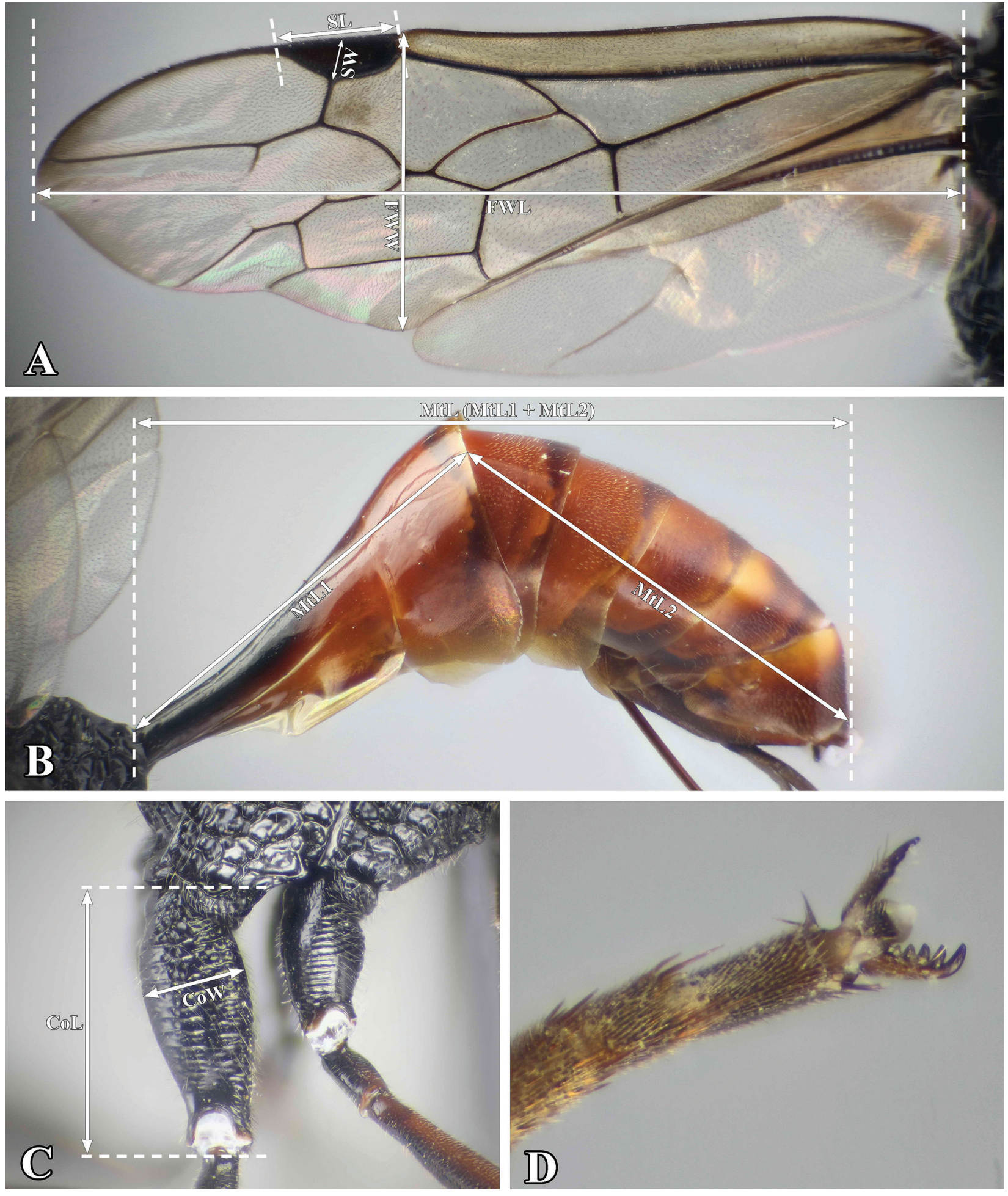

Figure 3. Pristaulacus compressus Spinola 1808. female (Iran): A fore and hind wing; B petiole and metasoma, lateral view; C hind coxa, lateral view; $\mathbf{D}$ hind claw, ventral view.

\section{Pristaulacus galitae (Gribodo, 1879) \#}

Aulacus galitae Gribodo, 1879: 339, Holotype 9. - Tunisia, Galita Island (CPTO).

Distribution. Algeria, Austria, Bulgaria, Canary Islands (Tenerife), Croatia, Cyprus, Czech Republic, France, Germany, Greece (including Crete and Rhodos), Hun- gary, Iran, Italy (including Sardinia and Sicily), Morocco, Poland, Romania, Russia (westernmost area), Slovakia, Spain, Tunisia (including Galita Island), Turkey, Ukraine and former Yugoslavia (Turrisi 2007, 2013a, Ghahari 2012, Huflejt and Wiśniowski 2012).

Distribution in Iran. East Azarbaijan province (Ghahari 2012: DU). 


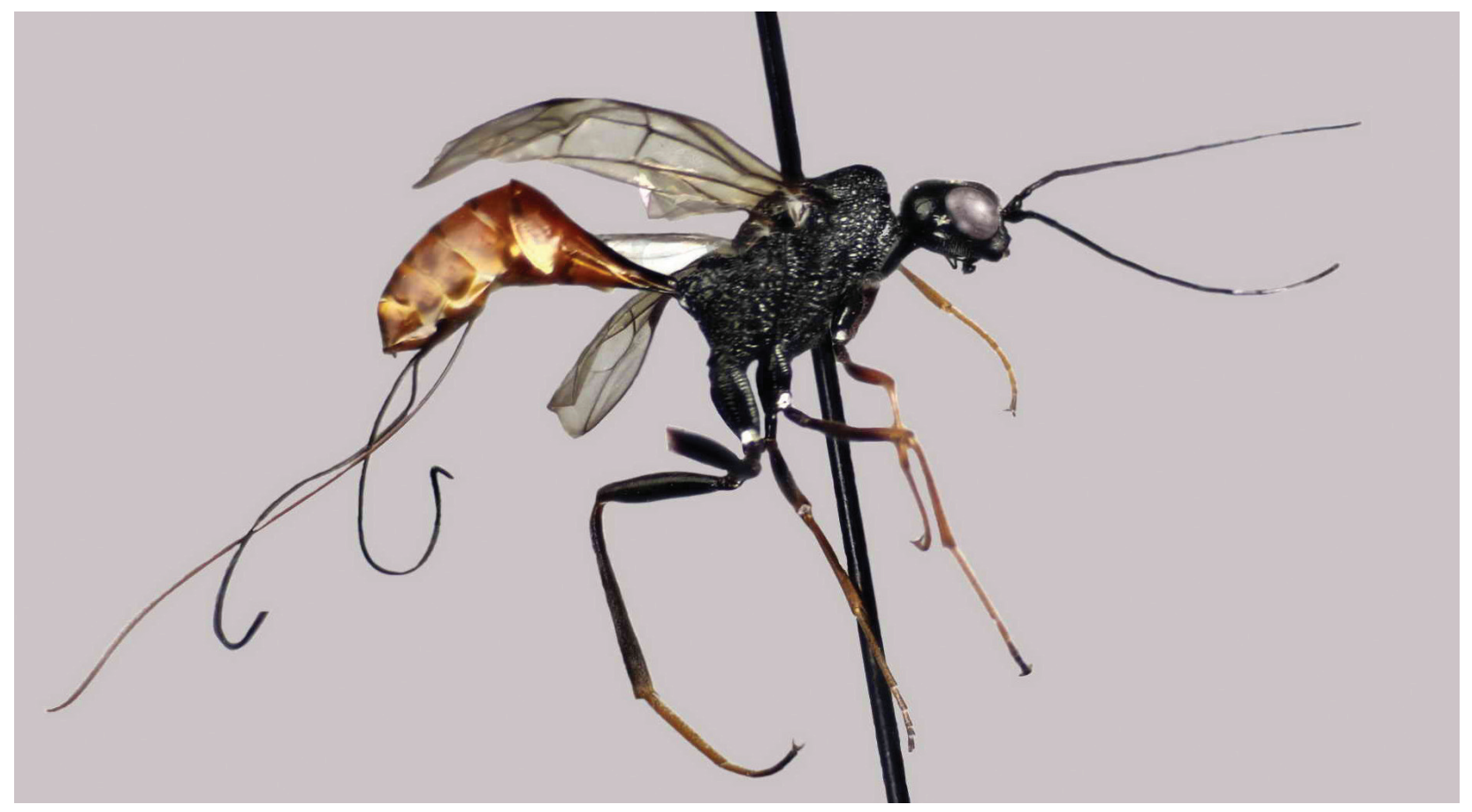

Figure 4. Pristaulacus compressus Spinola 1808. female (Iran): lateral habitus.

Diagnosis. $P$. galitae is a medium-sized species with a body length of 8.0-11.2 $\mathrm{mm}$ (excluding ovipositor), fore wing length $4.5-7.8 \mathrm{~mm}$. It is distinguished by the combination of the following features: shape of the head, with rounded profile of temple, occipital carina moderately wide $(0.5 \times \mathrm{OD})$, one anterior tooth-like process on each side of latero-ventral margin of pronotum, ovipositor length 1.0-1.2× fore wing length.

Hosts. Ghahari (2012) mentioned specimens reared in Iran from Trichoferus griseus \# (Fabricius, 1792) (Coleoptera, Cerambycidae) feeding on common fig, Ficus carica L. (Moraceae).

\section{Pristaulacus gloriator (Fabricius, 1804)}

Bassus gloriator Fabricius, 1804: 99, Holotype 9. - Germany, Habitat in Germ. Dom. Smidt (ZMUC).

Distribution. Albania, Austria, Czech Republic, Germany, Greece, Hungary, Iran, Italy, Poland, Romania, Russia (European and central areas), Slovakia, Turkey, former Yugoslavia (Turrisi 2007, 2013a, Huflejt and Wiśniowski 2012).

Distribution in Iran. Guilan province (Madl 1990: 114-115, NHMW; Turrisi 2007).

Diagnosis. $P$. gloriator is a medium to moderately largesized species with a body length of 10.2-15.0 mm (excluding ovipositor), fore wing length $8.2-11.8 \mathrm{~mm}$. It can be easily identified by the shape of the head with a narrow cerciniform occipital carina (width $0.2 \times \mathrm{OD}$ ), a rugulose-carinulate frons, latero-ventral margin of pronotum rounded without tooth-like processes, four tooth-like processes on the inner margin of tarsal claw, and light yellow tarsi.

Hosts. This species was reared from Paraclytus reitteri (Ganglbauer, 1881) (Coleoptera, Cerambycidae) feeding on alder, Alnus sp. The reared beetle is polyphagous in deciduous trees i.e. Acer, Alnus, Carpinus and Quercus (Miroshnikov 2014).

Remarks. This species was previously recorded as $P$. holzschuhi Madl, 1990 from Bandar-e Pahlavi (now called: Bandar-e Anzali - Anzali Port), Assalem, Guilan, Iran (Madl 1990), and is considered as a synonym of $P$. gloriator (Turrisi 2007) (type material examined and deposited in NHMW).

\section{Pristaulacus mourguesi Maneval, 1935 *}

Figs $5,6,7$

Pristaulacus mourguesi Maneval, 1935: 66, Holotype +. - France, Pont-Ravatgers (MNHN).

Specimens examined. $2 q$, DPPZ. Iran, Kermanshah province, Dudan, $35^{\circ} 01^{\prime} 00^{\prime \prime} \mathrm{N}, 46^{\circ} 11^{\prime} 32^{\prime \prime} \mathrm{E}, 1155 \mathrm{~m}$, 20.II.2016, BM-MTF-TS mounted in orchard, leg.: M. Zardouei Heidari; 1 , DPPZ. same locality label, 05.VI.2016, BM-MTF-TS mounted among Oak forest Quercus brantii Lindley, leg.: M. Zardouei Heidari.

Distribution. Croatia, France, Greece, Hungary (Turrisi 2007, 2013a), Iran (new record). 

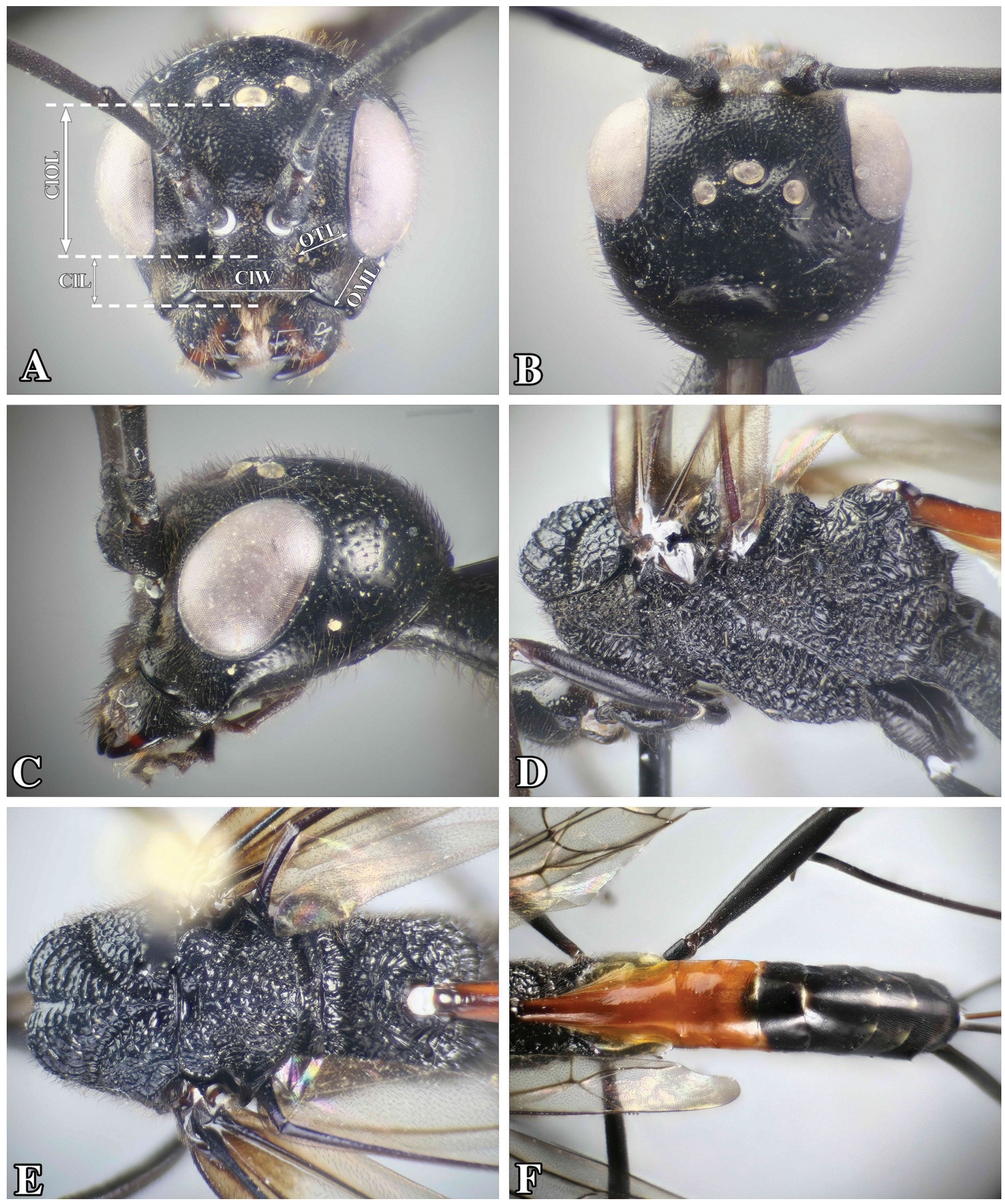

Figure 5. Pristaulacus mourguesi Maneval, 1935. female (Iran): A face, frontal view; B head, dorsal view; C head, lateral view; D mesosoma, lateral view; E mesosoma, dorsal view; F petiole and metasoma, dorsal view.

Distribution in Iran. Kermanshah province.

Diagnosis. P. mourguesi is one of the largest species among the Palaearctic Pristaulacus with a body length varying from 16.5 to $18.5 \mathrm{~mm}$ (excluding ovipositor), and fore wing length of $8.8-13.0 \mathrm{~mm}($ ( ) . It is distinguished by the shape of the head, narrow cerciniform occipital carina (width $0.2 \times$ ocellus diameter), hind basitarsus long and slightly curved, $1.5 \times$ length of tarsomeres $2-5$, and long ovipositor, $1.4-1.6 \times$ fore wing length.

Morphometric ratios. CIOL/CIL: 1.21; CIL/ClW: 2.75; CIW/OML: $0.78 ; \mathrm{CoL} / \mathrm{CoW}: 2.71 ; \mathrm{EL} / \mathrm{EW}: 2.65 ; \mathrm{EL} /$ OML: 2.72; EW/OOCL: 0.58; EW/OTL: 1.14; FWL/ 

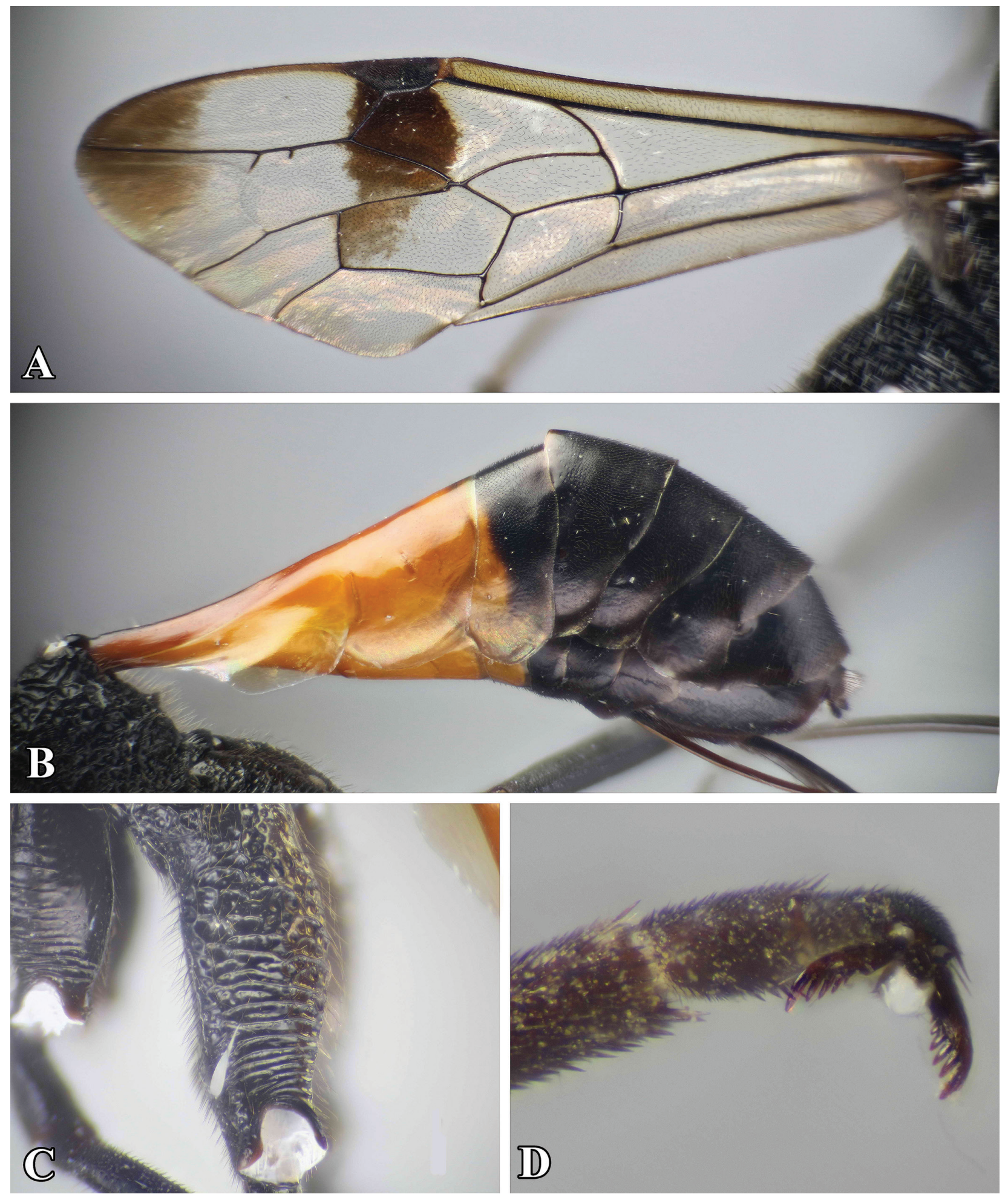

Figure 6. Pristaulacus mourguesi Maneval, 1935. female (Iran): A fore and hind wing; B petiole and metasoma, lateral view; C hind coxa, lateral view; D hind claw, ventral view.

FWW: 3.02; HL/CIL: 2.01; HL/TL: 1.97; HW/EW: 5.40; HW/HL: 1.27; IOL/CIOL: 1.27; IOL/EW: 3.26; IOL/HW: 0.60; IOL/OML: $3.35 ; \mathrm{MsL} / \mathrm{MsW}: 1.91 ; \mathrm{MtL} / \mathrm{MtW}: 6.39$; PEL/PEW: 2.39; PL/PW: 0.55; POL/OD: 2.08; POL/OOL: 1.33; SL/SW: 2.62; TL/EL: 0.80.

Hosts. Unknown (Turrisi 2007).
Remarks. This species was previously recorded only from Europe (Turrisi 2007, 2013a). There is a possible record for the Near East without source material (Madl 2012). The closest species is P. morawitzi (Semenow, 1892) being medium sized, punctures of head very fine, superficial, and scattered, metasoma pyriform, strongly compressed, nearly entirely reddish orange. See Turrisi (2007) for more details. 


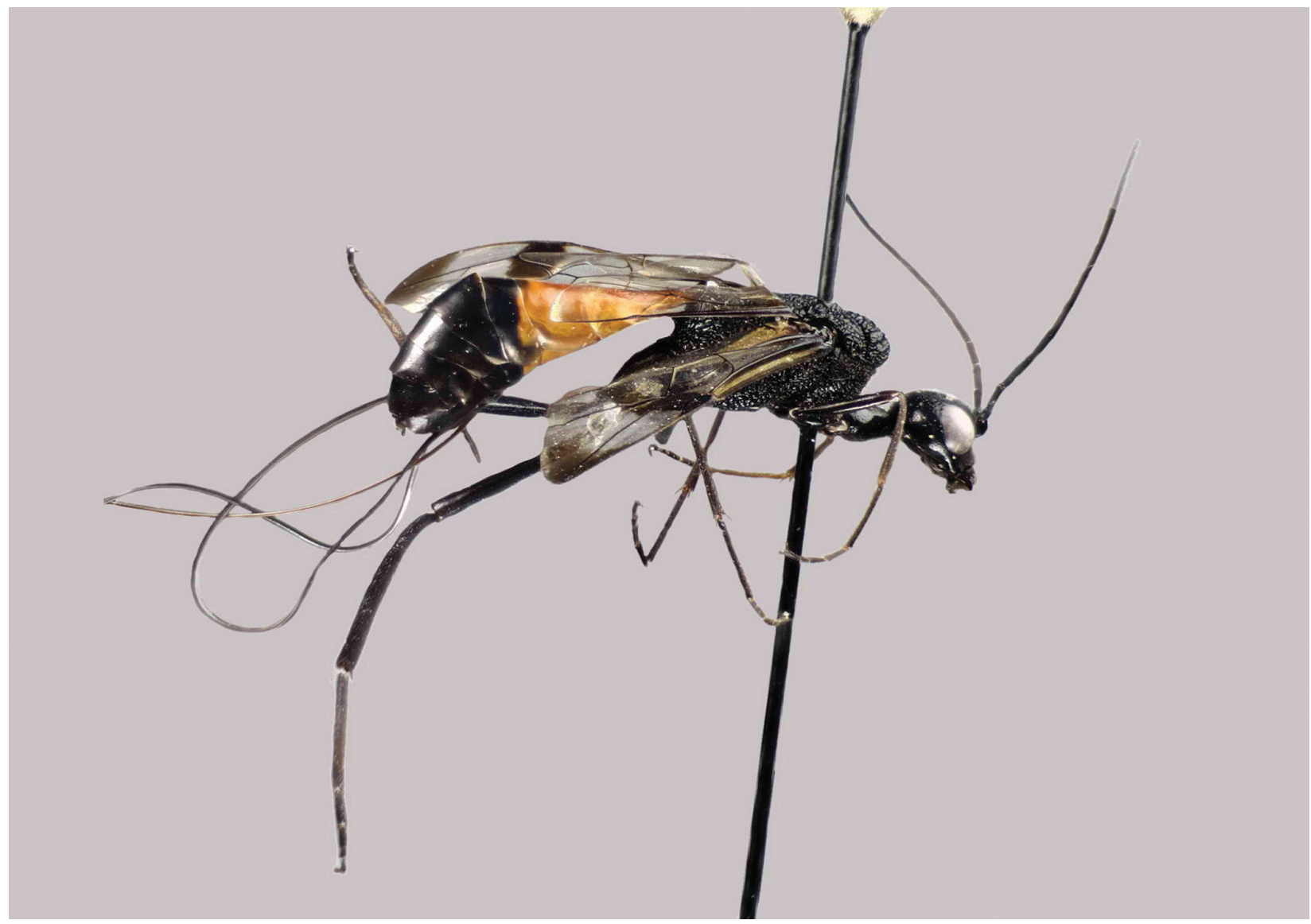

Figure 7. Pristaulacus mourguesi Maneval, 1935. female (Iran): lateral habitus.

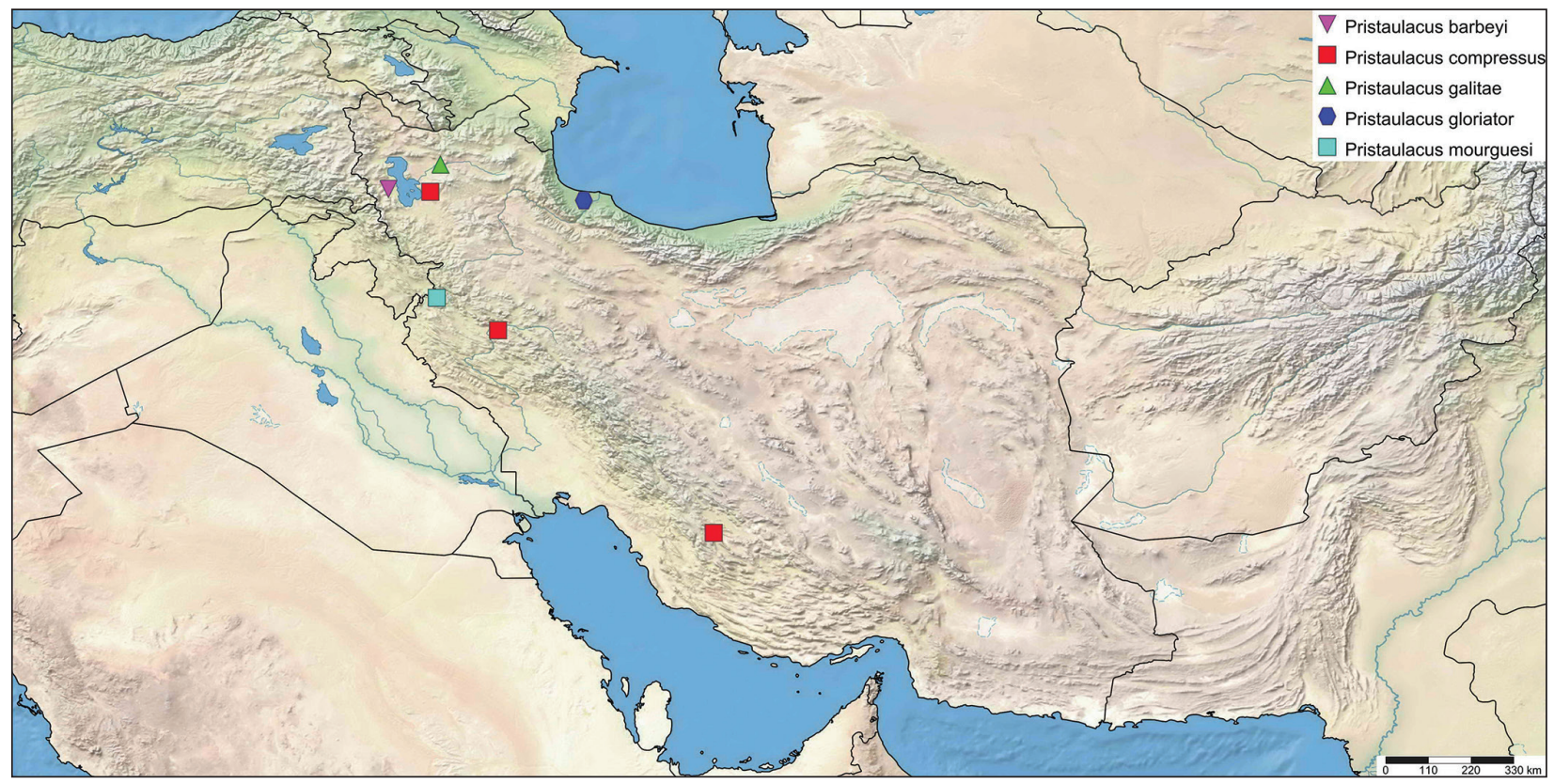

Figure 8. Distribution map of aulacid species in some provinces of Iran.

\section{Discussion}

The number of Iranian Aulacidae is raised to five, all within a single genus (Pristaulacus). All these species have been collected in Northern and Northwestern (forest habitat) regions, except $P$. compressus, which is recorded from Southern (subdesertic habitat) region.

Jennings et al. (2004) stated that remnant stands of forest are an ideal habitat for their wood-boring hosts. These wasps can be locally abundant in areas undergoing log- 
ging or forest fires. The rich fossil record of Aulacidae indicates they were quite abundant in the Mesozoic (Jennings and Austin 2004, Turrisi et al. 2009).

The new specimens have been collected in Zagros forests, which have an area of about 6 million hectares (3.5 percent of Iran), located in the west of Iran with a semi-arid to temperate climate. This wide territory is also referred to as western oak forests (oak-woodland), due to the dominancy of oak species (Quercus spp.). The species composition of the woodland vegetation depends on the climatic conditions (Zohary 1973, Kwandrans 2007).

The five species reported in this paper are distributed only in the Western part of the Palearctic region. The results of the present study clearly show the improved efficiency of modern collecting methods for Hymenoptera that are rarely collected with most conventional methods. In addition, the best collecting period seems to be June and this is consistent with those reported in Lotfalizadeh et al. (2017).

Although the research suggests a higher number of species in the Western territories of Iran we predict that the Eastern and Southern parts should also be quite species-rich. Further investigation, especially in poorly collected regions will probably increase the number of known species (Turrisi 2014). The species reported from Iran have ranges included in the Western part of the Palaearctic region. Given the poorly known faunistic situation, it is premature to discuss possible relationships among faunas of Iran and adjacent territories.

\section{Acknowledgements}

We are indebted to Ms. Maryam Zardouei Heidari (University of Zabol, Iran) for collecting the specimens and Mr. Amir Nabizadeh Sarabandi (University of Birjand, Iran) for his suggestion and advice on photographing. The authors also express their deep gratitude to Ehsan Rakhshani (University of Zabol, Iran) who offered constructive comments that significantly improved the manuscript. The Museum für Naturkunde Berlin kindly waived the author's fees for this manuscript. The authors thank the anonymous reviewers and the editor for the helpful comments on the manuscript.

\section{References}

van Achterberg C (2009) Can Townes type Malaise traps be improved? Some recent developments. Entomologische Berichten 69(4): 129-135.

Benoit PLG (1984) Aulacidae, famille nouvelle pour la faune de l'Afrique tropicale (Hymenoptera). Revue de Zoologie Africaine 98(4): 799-803.

Chen H-Y, Turrisi GF, Xu Z-f (2016) A revision of the Chinese Aulacidae (Hymenoptera, Evanioidea). ZooKeys 587: 77-124. https://doi. org/10.3897/zookeys.587.7207

Crosskey RW (1951) The morphology, taxonomy, and biology of the British Evanioidea (Hymenoptera). Transactions of the Royal Entomological Society London 102(5): 247-301. https://doi. org/10.1111/j.1365-2311.1951.tb00749.x
Fabricius JC (1792) Determinatio generis Ips affiniumque. Actes de la Société d'Histoire Naturelle de Paris 1: 27-35.

Fabricius JC (1804) Systema Piezatorum, Secundum Ordines, Genera, Species, Adiectis Synonymis, Loci, Observationibus, Descriptionibus. Brungsvigae, 440 pp.

Ferrière C (1933) Un nouvel Aulacidae Nord-africain (Hym.). Bulletin de la Société Entomologique de France 38: 140-143.

Ganglbauer L (1881) Bestimmungs-Tabellen der europaischen Coleopteran, IVa. Oedemeridae. Verhandlungen der Kaiserlich-Koniglichen Zoologisch-Botanischen Gesellschaft in Wien 31: 97-116.

Ghafouri Moghaddam M, Rakhshani E, Mokhtari A (2017) An upgrade pinning block: a mechanical practical aid for fast labelling of the insect specimens. Biodiversity Data Journal 5: e20648. https://doi. org/10.3897/BDJ.5.e20648

Ghafouri Moghaddam M, Ghafouri Moghaddam M, Rakhshani E, Mokhtari A (2017) An Upgrade Pinning Block: A Mechanical Practical Aid for Fast Labelling of the Insect Specimens. Biodiversity Data Journal 5: e20648. https://doi.org/10.3897/BDJ.5.e20648

Ghahari H (2012) Two new records of Aulacidae (Hymenoptera: Evanioidea) from Iran. Entomofauna 33: 273-278.

Ghahari H, Madl M (2017) An annotated catalogue of Iranian Aulacidae, Evaniidae and Gasteruptiidae (Hymenoptera: Evanioidea). Zootaxa 4338(2): 341-353. https://doi.org/10.11646/zootaxa.4338.2.8

Gribodo G (1879) Note imenotterologiche. Annali del Museo di Storia Naturale di Genova 14: 325-347.

Harris RA (1979) A glossary of surface sculpturing. Occasional Papers in Entomology 28: 1-31.

Holzschuh C (1974) Neue bockkäfer aus Pakistan, Iran, Anatolien und Mazedonien (Coleoptera: Cerambycidae). Zeitschrift der Arbeitsgemeinschaft Österreichischer Entomologen 25(3/4): 81-100. [In German]

Huber JT, Sharkey MJ (1993) Structure. In: Goulet H, Huber JT (Eds) Hymenoptera of the world: an identification guide to families. Agriculture Canada Research Branch, Monograph No. 1894E, Ottawa, Canada, 13-59.

Huflejt T, Wiśniowski B (2012) Materiały do znajomości krajowej fauny błonkówekz rodziny pokosowatych (Hymenoptera, Aulacidae). Nowy Pam Fizjogr 7(1-2): 25-34.

Jennings JT, Austin AD (2000) Higher-level phylogeny of the Aulacidae and Gasteruptiidae (Hymenoptera: Evanioidea). Hymenoptera: evolution, biodiversity and biological control. CSIRO Publishing, Collingwood, Australia, 154-164.

Jennings JT, Austin AD (2004) Biology and host relationships of aulacid and gasteruptiid wasps (Hymenoptera: Evanioidea): a review. In Rajmohana K, Sudheer K, Girish Kumar P, Santhosh S (Eds) Perspectives on Biosystematics and Biodiversity. (University of Calicut, Kerala, India): 187-215.

Jennings JT, Austin AD, Stevens NB (2004) First record of Aulacidae (Hymenoptera: Evanioidea) from New Caledonia with descriptions of three new species of Aulacus Jurine. Austral Entomology 43 (4): 346-352. https://doi.org/10.1111/j.1440-6055.2004.00418.x

Jurine L (1807) Nouvelle méthode de classer les hyménoptères et les diptères. Paschoud. Volume 1: 320 pp.

Kieffer JJ (1900) Note sur le genre Pristaulacus Kieff. (Hymén.). Bulletin de la Société entomologique de France 338-339.

Kwandrans J (2007) Diversity and ecology of benthic diatom communities in relation to acidity, acidification and recovery of lakes and rivers. Diatom Monographs 9: 1-169. 
Lotfalizadeh H, Masudi-Rad S, Mehrvar A (2017) Review of the superfamily Evanioidea (Hymenoptera) in Iran with four new records. Journal of Insect Biodiversity and Systematics 3(2): 141-151.

Madl M (1990) Über Aulacidae vom Iran (Hymenoptera, Evanioidea). Nachrichtenblatt der Bayerischen Entomologen 39(4): 114-116.

Madl M (2012) Fauna Europaea: Aulacidae. In Mitroiu MD, Madl M, Noyes J (ed) Fauna Europaea: Hymenoptera. by Fauna Europaea version 2.5, http://www.faunaeur.org [accessed 21 July, 2017]

Maneval H (1935) Observations sur des Hyménoptères de la faune Francaise et description d'une espèce nouvelle. Revue Française d'Entomologie 2: 65-76.

Miroshnikov A (2014) In: Konstantinov AS, Ślipiński SA, Solodovnikov Ayu. (Eds) Advances in studies on Asian cerambycids (Coleoptera: Cerambycidae). KMK Scientific Press Ltd., Krasnodar, Moscow, $51-71$.

Rohlf FJ (2006) tpsDig. Ver. 2.05. Stony Brook, NY, Department of Ecology and Evolution, State University of New York.

Semenow A (1892) Revisio Hymenopterorum Musei Zoologici Academiae Caesareae Scientiarum Petropolitanae. III. Familia Evaniidae. Bulletin des l'Académie Impériale des Sciences de St.-Pétersbourg, Nouvelle Serie 3, 35: 9-30.

Shorthouse DP (2010) SimpleMappr, an online tool to produce publication-quality point maps. [On Line]. Available from http://www. simplemappr.net [accessed on 19 September 2017]

Shuckard WE (1842) On the Aulacidae etc. The Entomologist, conducted by Edward Newmann, London.

Spinola M (1808) Insectorum Liguriae Species Novae aut Rariores quas in Agro Ligustico Nuper Detexit, Descripsit, et Iconibus Illustravit. Genuae, 262 pp.

Turrisi GF (2000) Gli Aulacidae di Sicilia, con descrizione di Pristaulacus lindae n. sp. (Hymenoptera Evanioidea). Bollettino della Società entomologica italiana 132 (3): 259-268.

Turrisi GF (2007) Revision of the Palaearctic species of Pristaulacus Kieffer, 1900 (Hymenoptera: Aulacidae). Zoota xa 1433: 1-76.

Turrisi GF (2011) Systematic revision of the sibling species belonging to the Pristaulacus compressus group (Hymenoptera: Aulacidae). Insect Systematics \& Evolution 42: 1-27. https://doi. org/10.1163/187631211X545132
Turrisi GF (2013a) Review of Aulacidae (Hymenoptera: Evanioidea) from Greece and Cyprus with new records. Entomologia Hellenica 22: 1-9. Turrisi GF (2013b) Pristaulacus barbeyi (Ferrière, 1933), new to Iberian Peninsula (Hymenoptera Aulacidae). Bollettino della Società Entomologica Italiana 145(3): 99-102. https://doi.org/10.4081/BollettinoSEI.2013.99

Turrisi GF (2013c) Addenda - Pristaulacus barbeyi (Ferrière, 1933), new to Iberian Peninsula (Hymenoptera Aulacidae). Bollettino della Società Entomologica Italiana 145(3): 99-102. https://doi.org/10.4081/ BollettinoSEI.2013.99

Turrisi GF (2014) A new species of Pristaulacus Kieffer, 1900 from Laos (Hymenoptera: Aulacidae). Natura Somogyiensis 24: 165-172.

Turrisi GF (2017) The parasitoid wasp family Aulacidae with a revised World checklist (Hymenoptera, Evanioidea). Proceedings of the Entomological Society of Washington 119(sp1): 931-939. https://doi. org/10.4289/0013-8797.119.SpecialIssue.931

Turrisi GF, Jennings JT, Vilhelmsen L (2009) Phylogeny and generic concepts in the parasitoid wasp family Aulacidae (Hymenoptera: Evanioidea). Invertebrate Systematics 23: 27-59. https://doi. org/10.1071/IS08031

Turrisi GF, Nobile V (2016) Description of Pristaulacus leleji sp. n. (Hymenoptera: Aulacidae) from Thailand. Evraziatskii Entomologicheskii Zhurnal 15: 152-155.

Wall I (1994) Seltene Hymenopteren aus Mittel-, West-und Sudeuropa (Hymenoptera Apocrita: Stephanoidea, Evanioidea, Trigonalyoidea). Entomofauna 15(14): 137-184.

Yu DSK, van Achterberg C, Horstmann K (2012) Taxapad 2012, Ichneumonoidea 2011. Database on flash-drive. Ottawa, Ontario, Canada. http://www.taxapad.com [accessed 17 september 2017]

Zhang JF, Rasnitsyn AP (2004) Minute members of Baissinae (Insecta: Hymenoptera: Gasteruptiidae) from the Upper Mesozoic of China and limits of the genus Manlaya Rasnitsyn, 1980. Cretaceous Research 25(6): 797-805. https://doi.org/10.1016/j.cretres.2004.08.001

Zhang HC, Zheng DR, Zhang Q, Jarzembowski EA, Ding M (2013) Re-description and systematics of Paraulacus sinicus Ping, 1928 (Insecta, Hymenoptera). Palaeoworld 22 (1-2): 32-35. https://doi. org/10.1016/j.palwor.2013.02.001

Zohary M (1973) Geobotanical Foundations of the Middle East, 2 volumes, Fischer, Stuttgart, Amsterdam. 